\title{
PADRÕES SINÓTICOS ASSOCIADOS A ONDAS DE FRIO NA CIDADE DE SÃO PAULO
}

\author{
GUSTAVO CARLOS JUAN ESCOBAR
}

\author{
Centro de Previsão de Tempo e Estudos Climáticos - CPTEC/INPE \\ Rodovia Presidente Dutra, km 40, SP-RJ, Cachoeira Paulista, SP, Brasil, CEP:12630-000. \\ E-mail: escobar@cptec.inpe.br
}

Recebido Novembro 2005 - Aceito Fevereiro 2007

\begin{abstract}
RESUMO
Neste trabalho foi feita uma classificação sinótica de seqüências de campos de pressão ao nível médio do mar (PNMM) e de altura geopotencial em $500 \mathrm{hPa}$ associada com a ocorrência de ondas de frio na cidade de São Paulo (SP). Para obter os padrões básicos de seqüências da PNMM e da altura geopotencial em $500 \mathrm{hPa}$ foi utilizada a metodologia de "Análise de Componentes Principais" (ACP) rotacionadas. Os resultados mostram três tipos de padrões de circulação de ondas de frio para a cidade de São Paulo durante o período 1960-2002 que representam aproximadamente $70 \%$ dos casos. O padrão dominante mostra o ingresso de anticiclones pósfrontais intensos em superfície, aproximadamente em $80^{\circ} \mathrm{W}, 45^{\circ} \mathrm{S}$, e a presença de uma crista em altitude no oceano Pacífico, próximo à costa do Chile, favorecendo a advecção de ar frio sobre o centro-sul do Brasil. O segundo padrão está associado a eventos de ciclogêneses no oceano Atlântico, na altura da região sul do Brasil, e a presença de uma configuração de bloqueio em altitude. Por último, observa-se um padrão relacionado com a passagem de frentes frias com trajetória predominantemente zonal, devido à presença de um intenso cavado orientado na direção quase meridional no sul do continente.
\end{abstract}

Palavras-chave: classificação sinótica, ondas de frio, componentes principais.

\begin{abstract}
SYNOPTIC CLASSIFICATION ASSOCIATED WITH COLD WAVES IN SÃO PAULO CITY.

In this work, a synoptic classification of sequence patterns of sea level pressure (SLP) and $500 \mathrm{hPa}$ geopotencial heights associated with cold waves over São Paulo city was carried out. The rotated "Principal Components Analysis" (PCA) is used to obtain the basic patterns of sequence of SLP and $500 \mathrm{hPa}$ geopotential heights. The results show three dominant types of patterns of circulation associated with cold waves in São Paulo city during 1960-2002 period, which explain $70 \%$ of the total variance. The dominant pattern represents the incursion of an intense postfrontal anticyclones in low level, close to $80^{\circ} \mathrm{W}, 45^{\circ} \mathrm{S}$, and a ridge over the Pacific ocean at upper level, producing cold air advection over central and southern Brazil. The second pattern is associated with occurrence of cyclogenesis forming in the Atlantic ocean, next to the southern Region of Brazil, with a blocking aloft configuration. Finally, it is observed a pattern related with the passage of a cold fronts with a zonally trajectory, due to the presence of a pronounced trough extending southward over the south of the continent.
\end{abstract}

Keywords: synoptic classification, cold wave, principal components. 


\section{INTRODUÇÃO}

Os acentuados declínios de temperatura associados às incursões de ar frio nas regiões sul e sudeste do Brasil têm grande impacto social, pois ocasionam prejuízos principalmente no setor agrícola. Durante o inverno, típicamente a região subtropical da América do Sul é afetada por fortes e bruscos declínios de temperatura, provocados pela passagem de sistemas frontais vindos do extremo sul do continente. A intensa massa de ar fria associada a esses sistemas frontais em algumas ocasiões tende a persistir por vários dias consecutivos gerando conseqüentemente ondas de frio. Os intensos anticiclones que acompanham essas fortes incursões de ar frio, contribuem para a importante perda de calor noturno por resfriamento radiativo, que geralmente está associado a baixo conteúdo de umidade e céu claro. Desta maneira, o ar frio se mantém por vários dias sem modificação, gerando condições favoráveis para ocorrência de geadas.

Esses fenômenos são muito freqüentes durante os meses de maio a setembro em toda a região sul e sudeste do Brasil (Parmenter 1976, Satyamurty et al. 1990, Seluchi e Nery 1992, Marengo et al. 1997, Vera e Vigliarolo 2000, Lupo et al. 2001, Satyamurty et al., 2002), onde produzem vários impactos na sociedade e também no setor produtivo do país. Por exemplo, as geadas ou os declínios acentuados de temperatura podem afetar as plantações de café em São Paulo provocando considerável aumento no preço deste produto no Mercado Internacional (Marengo et al. 1997).

Algumas vezes, o continente sul americano é influenciado por padrões anômalos de circulação que predominam durante períodos maiores que aqueles de escala sinótica. Por exemplo, eventos de bloqueios podem relacionar-se com condições de tempo caracterizado pelas incursões de ar frio no Brasil, principalmente nas regiões sul, sudeste e centro-oeste.

Existem diversos trabalhos na literatura sobre casos de onda de frio no Brasil, sendo que a maior parte deles são estudos sobre os aspectos sinóticos de uma frente fria intensa associada a geadas no centro-sul do Brasil (Fortune e Kousky 1983, Marengo et al. 1997, Seluchi e Nery 1992, Dapozzo e Silva Dias 1994, Satyamurti et al. 2002). Existem outros trabalhos que analisaram a estrutura média da troposfera média e alta associada a penetrações intensas de ar frio no sul e sudeste do Brasil. Vera e Vigliarolo (2000) mostraram a estrutura e evolução das perturbações de escala sinótica associadas à ocorrência de geadas no sul do Brasil. Eles encontraram, como características principais, a presença de uma perturbação ciclônica ingressando o continente sul americano por latitudes subpolares e outra perturbação ciclônica em níveis altos próxima à Cordilheira dos Andes, em latitudes subtropicais. Esta última perturbação é fator determinante para a ocorrência de ondas de frio em regiões tropicais.
Garreaud (2000) e Cavalcanti e Kousky (2003) analisaram a estrutura média tridimensional e a evolução das ondas de frio sobre América do Sul através da análise de composição de casos. Ambos autores mostraram que a amplificação de um padrão de onda em níveis médios, com uma crista sobre o Pacífico leste e um cavado sobre a América do Sul, fornece um sinal favorável para a ocorrência de ventos frios no centro-sul do continente sul-americano.

Lupo et al. (2001) fez uma classificação sinótica de ondas de frio na América do Sul através da composição de casos. As ondas de frio foram classificadas em três tipos em função da relação dos campos meteorológicos de superfície e altitude. $\mathrm{O}$ padrão de onda de frio Tipo 3 mostrou o anticiclone pós-frontal com lento deslocamento para leste e atingindo a região sul e o sul da região sudeste do Brasil. Em $500 \mathrm{hPa}$ observou-se a presença de uma fraca crista sobre o centro de América do Sul e uma fraca advecção de vorticidade anticiclônica, corrente abaixo dessa crista, que contribuiu para intensificação do anticiclone em superfície.

Pezza e Ambrizzi (2005) fizeram um estudo detalhado de eventos frios extremos atingindo a cidade de São Paulo nos últimos cem anos. Segundo os autores, o modelo padrão mais típico associado à ocorrência de geadas em São Paulo mostrou a presença de um ciclone extratropical no oceano na altura da costa do Brasil como principal mecanismo dinâmico.

A maioria dos trabalhos que analisam eventos frios, se baseiam na análise de composição de casos (compostos), e permitem compreender climatologicamente a circulação associada a este tipo de episódios a partir de campos médios. Porém, este tipo de metodologia não é suficiente para identificar as diferentes situações que conduzem à obtenção desse campo médio. Desta forma, para fins de prognóstico, as características médias não são suficientes para explicar a variabilidade da circulação (baixa, média e alta troposfera) associada à ocorrência de incursões de ar frio.

Escobar e Bischoff(1999), Muller et al. (2003) e Escobar (2004), realizaram uma classificação sinótica objetiva associada a incursões de ar frio e ocorrência de geadas na região central da Argentina utilizando a Análise por Componentes Principais (ACP). Segundo os autores, o modelo padrão mais típico associado à ocorrência de eventos frios na Argentina mostrou a presença de uma importante crista em níveis médios da atmosfera a oeste da costa do oceano Pacífico associada a um intenso anticiclone pós-frontal em superfície que advecta ar frio do sul do continente.

Considerando-se que a ocorrência de ondas de frio na região sudeste do Brasil estão estreitamente relacionadas com a variabilidade dos sistemas sinóticos que afetam o continente sul americano, este trabalho tem por objetivo estudar o comportamento regional da circulação atmosférica associada com eventos 
frios durante o inverno na cidade de São Paulo. A finalidade é fazer uma classificação sinótica desses eventos, possibilitando comprender a trajetória e desta forma contribuir para aprimorar a previsão de tempo.

Na seção 2, são apresentados os dados e a metodologia; na seção 3, os resultados da classificação sinótica e os processos físicos associados aos diferentes padrões de circulação obtidos, e a seção 4 apresenta uma síntese dos principais resultados obtidos deste trabalho.

\section{MATERIAL E MÉTODOS}

\subsection{Dados}

Para este estudo foram utilizados dados diários de temperatura mínima e máxima da estação meteorológica do Instituto de Astronomia, Geofísica e Ciências Atmosféricas da Universidade de São Paulo (SP)(IAG/USP), localizada na parte sul da cidade de São Paulo $\left(23,7^{\circ} \mathrm{S}, 46,6^{\circ} \mathrm{W}\right)$. Utilizou-se o período climatológico correspondente aos cinco meses mais frios do ano: maio, junho, julho, agosto e setembro (MJJAS) de 1960 até 2002. Durante este período são detectados declínios mais intensos de temperatura sobre o sudeste do Brasil que típicamente provocam grandes impactos na sociedade e no setor produtivo.

Para a análise dos campos de circulação em superfície e altitude associados a eventos frios em São Paulo foram usados os dados de pressão ao nível médio do mar e de altura geopotencial em $500 \mathrm{hPa}$, proveniente da reanálise do NCEP/NCAR (National Center for Environmental Prediction/National Center for Atmospheric Research) para o período 1960 a 2002 (Kalnay et al., 1996), disponíveis no endereço: www.cdc.noaa.gov.

\subsection{Critério de detecção de ondas de frio}

Existem diferentes critérios de seleção de casos associados a ondas de frio sendo que a maioria consideram a temperatura mínima e máxima diária (Gonçalves et al., 2002). Na agricultura, a temperatura mínima é a variável meteorológica mais comum e fundamental para a detecção de geadas. Dependendo do tipo de cultivo e de seu estado de florescimento, o limiar de temperatura mínima utilizada pode variar. Por exemplo, em São Paulo, a temperatura crítica (no abrigo meteorológico) para o café varia entre 0 e $2^{\circ} \mathrm{C}$ (Sentelhas et al., 1995). Outros critérios consideram, além da temperatura, a tendência diária da pressão atmosférica (Garreaud, 2000), já que após a passagem de uma intensa frente fria geralmente a pressão atmosférica sofre um importante aumento.

Por outro lado, as incursões de ar frio podem ser identificadas pela temperatura mínima no dia do evento e tendência de temperatura em relação às condições atmosféricas prévias (Escobar e Bischoff, 2001 e Escobar et al., 2004).

Neste trabalho, foi utilizado um critério de detecção de ondas de frio similar àquele de Escobar et al.(2004). Isto significa utilizar a magnitude do declínio diário de temperatura e priorizar o contraste térmico ao invés do valor absoluto da temperatura média ao longo do dia do evento.

Através dos dados diários de temperatura foram calculados os parâmetros estatísticos básicos das variáveis temperaturas mínimas, máximas, média diária e dos declínios diários de temperatura média diária. A temperatura média diária foi obtida como a média entre a temperatura mínima e a máxima. A partir destes cálculos aplicou-se um critério de detecção de ondas de frio, que considera a magnitude dos declínios de temperatura média diária e a temperatura mínima do dia de ocorrência do evento.

O declínio diário da temperatura média diária (DT) foi definido como:

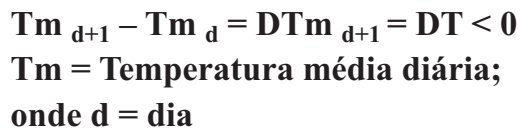

Da série total de dados obtida a partir desta definição, computaram-se todos os declínios diários sem estabelecer nenhum limiar. A seguir calculou-se a média $\left(\mathrm{DT}_{\mathrm{o}}\right)$ e o desviopadrão típico $\left(\sigma \mathrm{DT} \mathrm{T}_{0}\right)$ destes declínios. $\mathrm{E}$ a $\left(\mathrm{Tmin}_{0}\right)$ e respectivo desvio-padrão típico $\left(\sigma \operatorname{Tmin}_{0}\right)$ da temperatura mínima diária para os cinco meses analisados (MJJAS). A partir do cálculo desses parâmetros estatísticos definiu-se o critério de detecção de ondas de frio considerando as seguintes condições:

1. para cada mês, o declínio diário de temperatura media diária deve ser maior do que a média climatológica mais um desvio típico $\left(|\mathrm{DT}|>\left|\mathrm{DT}_{0}\right|+1 \sigma \mathrm{DT}_{0}\right)$.

2. para cada mês, a temperatura mínima diária do dia do evento deve ser menor do que a média climatológica menos um desvio típico $\left(\operatorname{Tmin}_{\mathrm{d} 0}<\operatorname{Tmin}_{0}-1 \sigma \operatorname{Tmin}_{0}\right)$.

$\mathrm{DT}=$ declínio diário de temperatura média diária.

$\mathrm{DT}_{0}=$ declínio diário de temperatura média diária climatológico (1960 / 2002).

$\operatorname{Tmin}_{\mathrm{d} 0}=$ temperatura mínima diária do dia do evento.

$\operatorname{Tmin}_{0}=$ temperatura mínima diária climatologica para cada mês (1960 / 2002).

$\sigma=$ desvio típico.

\subsection{Determinação dos principais modos de circulação atmosférica em superfície e altitude associada com ondas de frio na cidade de São Paulo.}

\subsubsection{Análise de Componentes Principais (ACP)}

A partir das datas dos dias associados a eventos frios em São Paulo, obtidas segundo a aplicação do critério referido em 2.2 foram selecionadas as situações sinóticas utilizando 
os campos de pressão ao nível do mar e os campos de altura geopotencial em $500 \mathrm{hPa}$ provenientes do NCEP.

Para a determinação dos padrões associados a esses eventos frios foi realizada uma classificação sinótica das seqüências de campos de pressão ao nível do mar e de altura geopotencial em $500 \mathrm{hPa}$. A seqüência foi formada pelo campo de circulação dois dias antes do evento (dia -2), um dia antes (dia -1) e o dia do evento (dia 0). A metodologia utilizada foi a ACP com uma matriz de correlação em Modo - T (Green, 1978; Richman, 1986). Existem dois tipos de ACP utilizados para analisar a variável observada tanto no espaço quanto no tempo. O primeiro chamado Modo-S está relacionado com a análise de séries temporais correspondentes a pontos no espaço. Isto significa que a variável estatística analisada corresponde a séries temporais de uma variável meteorológica que pode ser considerada contínua no espaço e no tempo. Por outro lado, o Modo-T pode ser aplicado para classificar campos atmosféricos espaciais (Compagnucci e Salles, 1997, Escobar, 2004). Segundo Richman (1983) o Modo-T é uma ferramenta muito útil para sintetizar e reproduzir padrões de circulações, quantificando sua freqüência e mostrando os períodos de tempo neles dominantes.

Os Padrões de Seqüências Principais (PSP) foram obtidos usando a aproximação de Compagnucci et al. (2001). Nesta aplicação as variáveis são seqüências de padrões espaciais de pressão ao nível do mar e de altura geopotencial em $500 \mathrm{hPa}$, que correspondem a um evento frio, e, a matriz de correlação representa a correlação entre seqüências para cada evento. Esta aproximação é considerada como uma extensão do tradicional ACP, com uma matriz de correlação em Modo-T, cujo objetivo principal é obter a evolução dos principais modos dominantes de circulação que permitam analisar a trajetória e comportamento dos sistemas sinóticos sobre determinadas áreas.

Após a aplicação desta aproximação foi feita a rotação Varimax. A rotação das componentes principais tem como principal objetivo redistribuir a variância total dos dados utilizados com o intuito de facilitar o significado físico das componentes obtidas (Richman, 1986). Para a determinação do número de componentes rotacionadas utilizou-se a regra do autovalor 1.0 (Richman et al., 1992).

Para a determinação das situações meteorológicas altamente correlacionadas com as componentes principais foram utilizadas as series temporais de "factor loadings" que representam as correlações entre cada variável (situação meteorológica real) e cada componente principal (Richman, 1986). A análise da série de "factor loadings" permite determinar a representatividade das componentes principais como situações sinóticas reais, valores próximos a 1 representam seqüências de situações meteorológicas similares às seqüências das componentes principais obtidas (Harman, 1976; Cattel, 1978).

\section{RESULTADOS}

\subsection{Critério de deteç̧ão de ondas de frio}

A Tabela 1 mostra os resultados dos cálculos estatísticos das variáveis utilizadas para São Paulo - SP e a Tabela 2 apresenta as datas selecionadas uma vez aplicado o critério de detecção de ondas de frio.

Tabela 1 - Declínio diário de temperatura média diária(DT)(sombreado) e temperatura mínima $\left(\operatorname{Tmin}_{\mathrm{d} 0}\right)$ (sombreado) considerada no dia do evento frio para a cidade de São Paulo para o período de 1960-2002 segundo o critério estabelecido em 2.2. $\mathrm{DT}_{0}=$ declínio diário de temperatura média diária climatológico (1960/2002). Tmin $\operatorname{Tm}_{0}=$ temperatura mínima diária climatologica para cada mês (1960 / 2002). $\sigma=$ desvio típico.

\begin{tabular}{cccccc}
\hline & Maio & Junho & Julho & Agosto & Setembro \\
\hline $\mathrm{DT}_{0}$ & $-1,6$ & $-1,7$ & $-2,0$ & $-2,4$ & $-2,6$ \\
$\sigma \mathrm{DT}_{0}$ & 1,6 & 1,6 & 2,3 & 2,3 & 2,4 \\
$\mathrm{DT}$ & $-3,2$ & $-3,3$ & $-4,3$ & $-4,7$ & $-5,0$ \\
$\mathrm{Tmin}_{0}$ & 13,0 & 11,5 & 11,0 & 11,8 & 13,0 \\
$\sigma \mathrm{Tmin}_{0}$ & 2,7 & 2,7 & 3,4 & 2,6 & 2,4 \\
$\operatorname{Tmin}_{\mathrm{d} 0}$ & 10,3 & 8,8 & 7,6 & 9,2 & 10,6 \\
\hline
\end{tabular}

A Tabela 1 mostra um significativo aumento em módulo dos DT a partir de Julho, associados principalmente ao aumento em módulo dos $\mathrm{DT}_{0}$ e do $\sigma \mathrm{DT}_{0}$. Uma possível explicação associada a este comportamento pode ser o aumento do balanço radiativo entre o final do inverno e o início da primavera sobre a região subtropical do Brasil. Isto significa um expressivo aumento das temperaturas máximas, e em conseqüência, também das temperaturas médias diárias. Desta maneira, o declínio de temperatura que provoca a passagem de uma frente fria a partir do mês de Julho será maior daquele provocado durante os meses de Maio e Junho. Uma explicação mais detalhada em relação ao comportamento dos declínios diários de temperatura média diária pode-se encontrar em Escobar et al. (2001).

A aplicação deste critério identificou 101 casos de incursões de ar frio na cidade de São Paulo, dos quais 21 deles corresponderam ao mês de maio, 20 em junho, 16 em julho, 22 em agosto e 22 em setembro (Tabela 2 ).

\subsection{Situações sinóticas associadas com ondas de frio na cidade de São Paulo}

\subsubsection{Pressão ao nível do mar}

A aplicação da Análise de Componentes Principais identificou três PSP em superfície que explicaram aproximadamente $70 \%$ da variância total.

A Tabela 3 mostra as porcentagens da variância explicada por cada componente e porcentagens da variância acumulada pelas componentes. 
Tabela 2 - Datas correspondentes aos dias escolhidos para a realização da classificação sinótica associada a ondas de frio na cidade de São Paulo.

\begin{tabular}{|c|c|c|c|c|c|c|c|c|}
\hline Data & $\operatorname{Tmin}_{\mathrm{d} 0}$ & DT & Data & $\operatorname{Tmin}_{\mathrm{d} 0}$ & DT & Data & $\operatorname{Tmin}_{\mathrm{d} 0}$ & DT \\
\hline $11 / 5 / 60$ & 8,5 & $-4,2$ & $19 / 6 / 81$ & 3,8 & $-6,8$ & $2 / 8 / 83$ & 8,7 & $-5,9$ \\
\hline $20 / 5 / 61$ & 8,9 & $-7,9$ & $15 / 6 / 83$ & 8,0 & $-4,6$ & $25 / 8 / 84$ & 6,5 & $-9,2$ \\
\hline $4 / 5 / 62$ & 9,6 & $-4,0$ & $28 / 6 / 84$ & 8,4 & $-3,9$ & $12 / 8 / 85$ & 8,3 & $-5,8$ \\
\hline $29 / 5 / 62$ & 8,5 & $-4,2$ & $23 / 6 / 87$ & 8,0 & $-6,3$ & $7 / 8 / 87$ & 6,6 & $-4,7$ \\
\hline $4 / 5 / 63$ & 8,0 & $-6,2$ & $25 / 6 / 94$ & 6,2 & $-6,7$ & $10 / 8 / 88$ & 8,4 & $-8,6$ \\
\hline $1 / 5 / 68$ & 7,3 & $-7,6$ & $21 / 6 / 00$ & 7,7 & $-6,8$ & $28 / 8 / 90$ & 8,2 & $-5,1$ \\
\hline $16 / 5 / 68$ & 6,7 & $-6,5$ & $27 / 6 / 01$ & 6,6 & $-3,8$ & 2/8/91 & 5,6 & $-9,9$ \\
\hline $12 / 5 / 73$ & 6,0 & $-5,4$ & $6 / 7 / 62$ & 5,8 & $-5,8$ & $2 / 8 / 92$ & 7,9 & $-8,5$ \\
\hline $28 / 5 / 74$ & 8,5 & $-4,1$ & $11 / 7 / 65$ & 2,1 & $-6,7$ & $10 / 8 / 93$ & 9,0 & $-7,5$ \\
\hline $16 / 5 / 77$ & 9,6 & $-5,7$ & $2 / 7 / 70$ & 5,5 & $-8,2$ & $3 / 8 / 94$ & 5,7 & $-9,8$ \\
\hline $31 / 5 / 78$ & 6,3 & $-6,8$ & $8 / 7 / 72$ & 5,6 & $-4,5$ & 14/8/99 & 6,2 & $-9,6$ \\
\hline $30 / 5 / 79$ & 5,8 & $-6,6$ & $6 / 7 / 75$ & 5,4 & $-4,8$ & $4 / 8 / 00$ & 7,3 & $-5,5$ \\
\hline $31 / 5 / 84$ & 9,5 & $-3,4$ & $17 / 7 / 75$ & 1,2 & $-12,6$ & $1 / 9 / 60$ & 8,0 & $-9,4$ \\
\hline $25 / 5 / 87$ & 6,3 & $-6,0$ & $15 / 7 / 76$ & 6,4 & $-5,8$ & $2 / 9 / 64$ & 7,9 & $-11,2$ \\
\hline $31 / 5 / 88$ & 7,0 & $-3,2$ & $11 / 7 / 85$ & 6,6 & $-5,4$ & 7/9/73 & 8,2 & $-7,4$ \\
\hline $26 / 5 / 89$ & 8,6 & $-5,6$ & $6 / 7 / 89$ & 6,8 & $-8,3$ & $6 / 9 / 74$ & 10,2 & $-7,9$ \\
\hline $18 / 5 / 90$ & 7,7 & $-7,9$ & $11 / 7 / 90$ & 7,3 & $-5,1$ & $9 / 9 / 74$ & 5,5 & $-7,7$ \\
\hline $22 / 5 / 90$ & 6,3 & $-5,3$ & $28 / 7 / 90$ & 2,4 & $-8,4$ & $16 / 9 / 80$ & 8,4 & $-7,8$ \\
\hline 20/5/99 & 9,2 & $-3,9$ & $31 / 7 / 93$ & 6,4 & $-5,7$ & $22 / 9 / 80$ & 7,4 & $-6,6$ \\
\hline $30 / 5 / 99$ & 9,2 & $-6,5$ & 9/7/94 & 2,3 & $-8,4$ & $5 / 9 / 81$ & 10,2 & $-5,4$ \\
\hline $5 / 5 / 01$ & 9,7 & $-7,4$ & $21 / 7 / 96$ & 7,2 & $-5,0$ & $30 / 9 / 81$ & 9,0 & $-8,3$ \\
\hline $25 / 6 / 60$ & 7,1 & $-4,3$ & $28 / 7 / 01$ & 5,1 & $-7,8$ & $2 / 9 / 83$ & 10,2 & $-7,3$ \\
\hline $15 / 6 / 61$ & 8,3 & $-4,2$ & $17 / 7 / 02$ & 6,8 & $-4,9$ & $8 / 9 / 83$ & 9,1 & $-5,5$ \\
\hline $11 / 6 / 62$ & 5,1 & $-3,4$ & $23 / 8 / 62$ & 8,8 & $-5,5$ & $20 / 9 / 83$ & 9,4 & $-5,6$ \\
\hline $6 / 6 / 64$ & 4,1 & $-5,4$ & $5 / 8 / 63$ & 6,0 & $-8,1$ & $2 / 9 / 85$ & 9,9 & $-5,4$ \\
\hline $13 / 6 / 64$ & 3,8 & $-6,5$ & $20 / 8 / 65$ & 6,5 & $-9,1$ & $3 / 9 / 87$ & 9,2 & $-5,9$ \\
\hline $17 / 6 / 64$ & 8,1 & $-7,0$ & $6 / 8 / 66$ & 4,0 & $-8,6$ & $16 / 9 / 89$ & 8,7 & $-5,9$ \\
\hline $29 / 6 / 64$ & 7,6 & $-5,1$ & $8 / 8 / 70$ & 7,8 & $-8,8$ & $13 / 9 / 90$ & 9,0 & $-9,0$ \\
\hline $4 / 6 / 69$ & 4,8 & $-4,0$ & $31 / 8 / 72$ & 8,3 & $-6,7$ & $24 / 9 / 90$ & 9,7 & $-5,4$ \\
\hline $23 / 6 / 72$ & 6,6 & $-4,1$ & $6 / 8 / 74$ & 8,3 & $-5,7$ & $20 / 9 / 95$ & 10,5 & $-9,5$ \\
\hline $19 / 6 / 73$ & 6,2 & $-5,8$ & $16 / 8 / 74$ & 5,1 & $-8,3$ & $10 / 9 / 96$ & 10,3 & $-5,1$ \\
\hline $7 / 6 / 75$ & 6,0 & $-7,2$ & $14 / 8 / 76$ & 6,8 & $-6,6$ & $25 / 9 / 00$ & 10,0 & $-10,8$ \\
\hline $11 / 6 / 77$ & 8,4 & $-4,1$ & $24 / 8 / 78$ & 8,4 & $-9,5$ & $21 / 9 / 02$ & 10,3 & $-6,5$ \\
\hline $27 / 6 / 80$ & 6,9 & $-3,8$ & 3/8/82 & 8,6 & $-7,1$ & & & \\
\hline
\end{tabular}


Tabela 3 - Porcentagens da variância explicada e porcentagens da variância acumulada pelos três PSPs.

\begin{tabular}{ccc}
\hline PSP & Por. Var. (\%) & Por. Cum. Var. (\%) \\
\hline $1^{\circ}$ & 29,3 & 29,3 \\
$2^{\circ}$ & 21,8 & 51,1 \\
$3^{\circ}$ & 18,7 & 69,8 \\
\hline
\end{tabular}

A análise das componentes de peso (ou “factor loadings") permite avaliar a representatividade dos padrões como situações sinóticas reais. Valores próximos a 1 representam seqüências de situações meteorológicas similares às seqüências dos padrões obtidos (Harman, 1976; Cattel, 1978). As primeiras três componentes de peso mostraram valores maiores que 0,7 . Isto significa que os padrões de seqüência teóricos e as situações sinóticas reais têm configurações similares. Os demais PSP não foram considerados neste trabalho já que explicam menos de $5 \%$ da variância. Esses padrões também representam situações meteorológicas especiais, porém menos freqüentes.

Nas Figuras 1 a 3 observam-se as (a) três PSP e (b) casos observados altamente correlacionados com eles.

O primeiro Padrão (Figura 1a), PSP1, mostra o avanço de uma frente fria típica que chega à Região Sudeste do Brasil no dia -1. No dia -2 o centro de baixa pressão associado a esta frente fria encontra-se posicionado aproximadamente em $52^{\circ} \mathrm{S}$, $38^{\circ} \mathrm{W}$ e simultaneamente o anticiclone pós-frontal situado no sul do Chile, altura de $50^{\circ} \mathrm{S}$. Este anticiclone associado à massa de ar frio desloca-se para nordeste chegando ao Estado de São Paulo no dia 0 , momento em que provoca declínio significativo de temperatura. Pode-se observar também que neste mesmo dia o sistema frontal chegou aos Estados do Rio de Janeiro e Minas Gerais.

Com esta configuração de pressão em superfície, o anticiclone avança até latitudes mais baixas, atingindo também boa parte da Região Centro-Oeste e o extremo sudoeste da Região Norte do Brasil. A análise da configuração de pressão em superfície associada a este modelo padrão de seqüência, também permite inferir que a massa de ar fria, que atinge grande parte do Estado de São Paulo, apresenta uma forte componente marítima devido ao intenso gradiente zonal de pressão, observado sobre o oceano Atlântico a partir do dia -1. Este comportamento faz com que as características da massa de ar frio se modifiquem ao longo do seu percurso, chegando à região de estudo um pouco mais enfraquecida.

O segundo Padrão (Figura 2a), PSP2, mostra a evolução e desenvolvimento de uma onda frontal no oceano Atlântico, na altura da Região Sul do Brasil. Este processo é conhecido como ciclogênese. Durante o dia -2 observa-se uma região de baixa a)

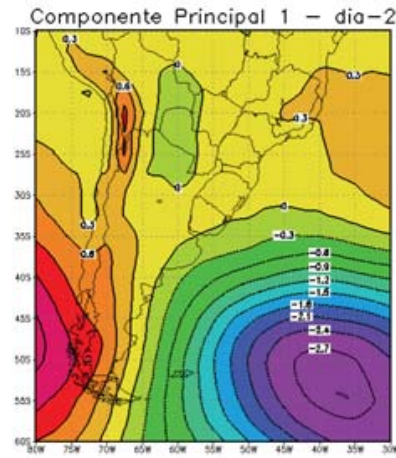

b)

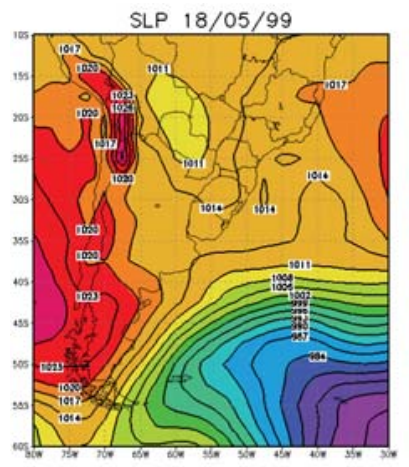

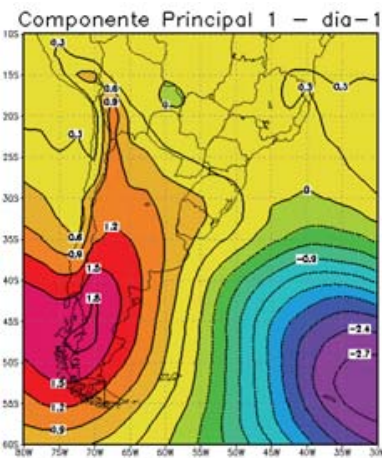

SLP $19 / 05 / 99$

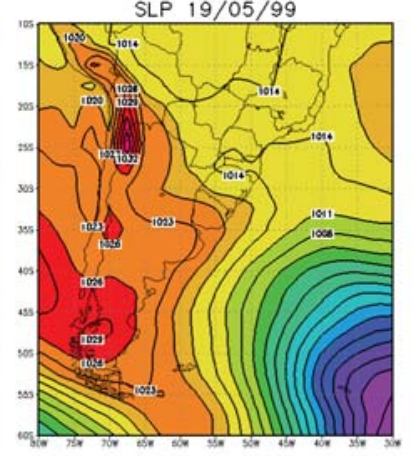

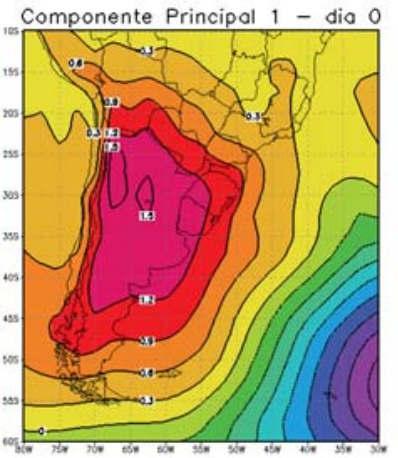

SLP $20 / 05 / 99$

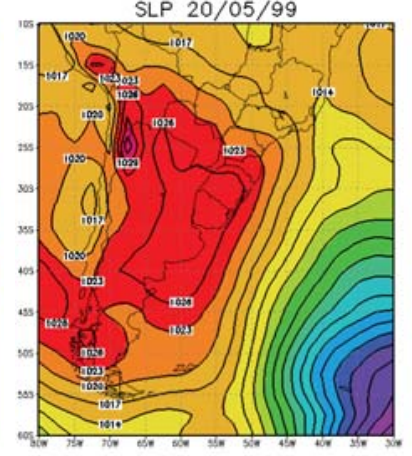

Figura 1 - (a) Primeira Seqüência de Componentes Principais (PSP1) e (b) um caso observado de pressão em superfície altamente correlacionado (8/05/99 - 20/05/99). 
pressão relativa no oceano Atlântico na altura do Sul do país. Simultaneamente, observa-se um anticiclone centrado a leste da Patagônia, Argentina, aproximadamente em $45^{\circ} \mathrm{S}, 60^{\circ} \mathrm{W}$. Este padrão de circulação em superfície esteve associado à atuação de uma frente fria localizada ao norte do sul do Brasil. Esse sistema frontal se mantém estacionário nessa região e a partir do dia -1 a região de baixa pressão relativa começa a aprofundar-se e deslocar-se para sudeste, com seu centro em $32^{\circ} \mathrm{S}, 47^{\circ} \mathrm{W}$, dando início á ciclogenêse. No dia 0 , o ciclone extratropical continua organizado e seu ramo frio associado favorece a entrada do ar mais frio sobre a região Sudeste e parte das regiões centro-oeste e norte do Brasil.

Durante este processo, o ar mais frio que se encontra a oeste do sistema de baixa pressão atinge o Estado de São Paulo com maior intensidade, provocando um declínio significativo de temperatura. Entre os dias -1 e 0, o anticiclone posicionado ao sul da onda frontal afasta-se lentamente para leste, acompanhando a evolução do processo ciclogenético. No decorrer destes dias (-1 e 0) pode-se observar um aumento da pressão atmosférica no Estado de São Paulo, associado com o desenvolvimento da onda frontal e o ingresso do ar mais frio. Esta situação meteorológica também está associada com fortes declínios de temperatura no oeste do estado de Mato Grosso, nos estados de Rondônia e Acre e no sudoeste do estado do Amazonas, fenômeno conhecido como "friagem".

Uma diferença que pode ser notada entre o padrão PSP2 e o PSP1 é a trajetória do ar frio. Apesar das figuras não mostarem as trajetórias de massas de ar, é possível inferir qualitativamente através dos campos de pressão, que no PSP1 o ar apresenta características marítimas, devido a sua trajetória mais oceânica. No PSP2 o ar é mais seco, já que entra pelo interior do continente, o que permite que as propriedades do ar não sejam modificadas significativamente em seu percurso. Embora esta última característica seja uma hipótese inferida apenas do campo de pressão ela favorece à ocorrência de declínios de temperaturas mais intensos quando a massa fria chega ao Estado de São Paulo.

O terceiro padrão, PSP3, mostrado na Figura 3 apresenta o avanço de uma frente fria com trajetória predominantemente zonal.

No dia -1 o sistema frontal frio encontra-se no centro da Argentina e rapidamente desloca-se para o oceano Atlântico no dia 0 . A característica principal deste modelo de circulação é o rápido deslocamento de oeste para leste do anticiclone pósfrontal que entra no continente próximo a $30^{\circ} \mathrm{S}$, ou seja, mais ao norte que o observado nos casos anteriores (PSP1 e PSP2). a)

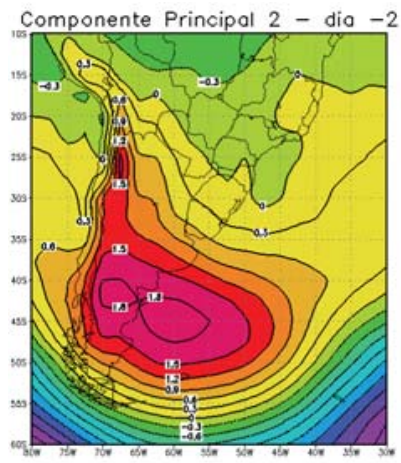

b)

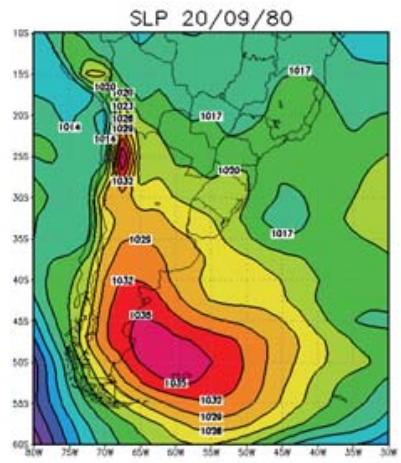

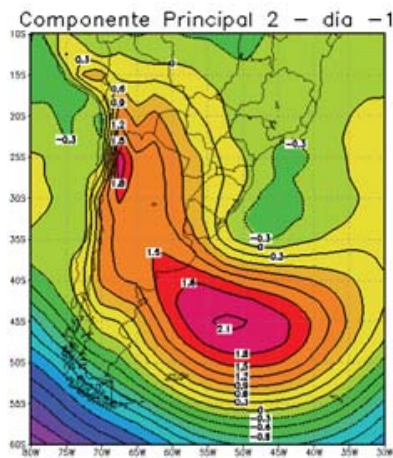

SLP $21 / 09 / 80$

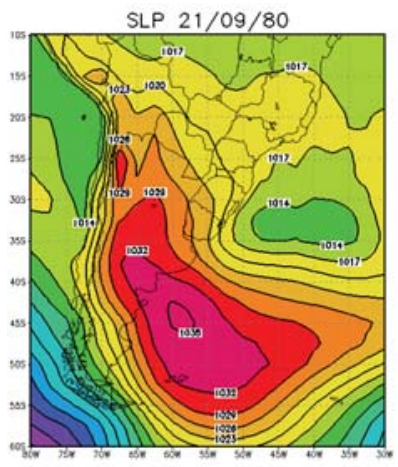

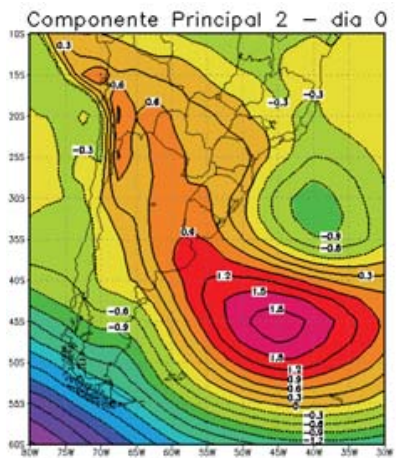

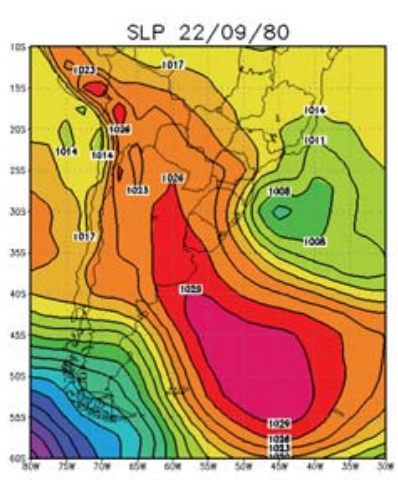

Figura 2 - (a) Segunda Seqüência de Componentes Principais (PSP 2) e (b) um caso observado de pressão em superfície altamente correlacionada $(20 / 09 / 80-22 / 09 / 80)$. 
Com esse padrão de circulação em superfície, o anticiclone pós-frontal mantém características continentais o que favorece a intensificar a perda radiativa durante a noite e em consequência provocar temperaturas mínimas mais baixas.

\subsubsection{Altura geopotencial em $500 \mathrm{hPa}$}

A análise da altura geopotencial em $500 \mathrm{hPa}$ foi feita porque este nível representa a atmosfera média e tem a importante característica de guiar sistemas meteorológicos que atuam em superfície, tendo como conseqüência uma grande importância na previsão do tempo.

A aplicação da ACP identificou três padrões de circulação em altitude que explicaram 94,5\% da variância total. A Tabela 4 mostra as porcentagens da variância explicada e porcentagens da variância acumulada pelas componentes.

Tabela 4 - Porcentagens da variância explicada e porcentagens da variância acumulada pelos três PSPs.

\begin{tabular}{ccc}
\hline PSP & Por. Var. (\%) & Por. Cum. Var. (\%) \\
\hline $1^{\circ}$ & 36,2 & 36,2 \\
$2^{\circ}$ & 35,2 & 71,4 \\
$3^{\circ}$ & 23,1 & 94,5 \\
\hline
\end{tabular}

As Figuras 4 a 6 mostram os (a) três padrões e (b) casos observados altamente correlacionados com eles.

O primeiro padrão, PSP1, apresentado na Figura 4a mostra um importante vórtice ciclônico que abrange uma ampla área do oceano Atlântico Sul, centrado aproximadamente a leste da Patagônia Argentina. Desse sistema de baixa pressão se estende um cavado, bem inclinado, em direção ao continente que atinge a região central da Argentina. A oeste desse cavado pode-se notar uma área de alta pressão sobre o oceano Pacífico Sul, próximo à costa sul do Chile. Os dois sistemas meteorológicos (baixa e alta), determinam um sistema de onda longa, com pequeno deslocamento para leste e que se amplifica e intensifica no decorrer dos dias analisados. Este padrão de circulação em níveis médios da atmosfera estaria associado a uma situação típica de bloqueio a sudoeste do continente sulamericano (Sinclair, 1996).

Com a configuração de ventos em $500 \mathrm{hPa}$, mostrada na Figura 4, o ar frio que vem do sul do continente, é conduzido para o norte atingindo latitudes mais baixas. Desta maneira, a massa de ar frio chega ao centro-sul do Brasil provocando fortes declínios de temperatura.

A seqüência observada de altura geopotencial correspondente aos dias 14, 15 e 16/05/77 (Figura 4b) apresenta uma a)

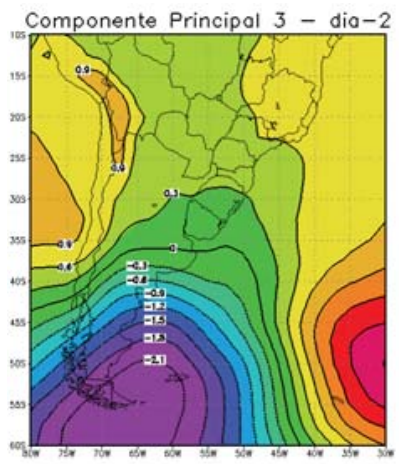

b)

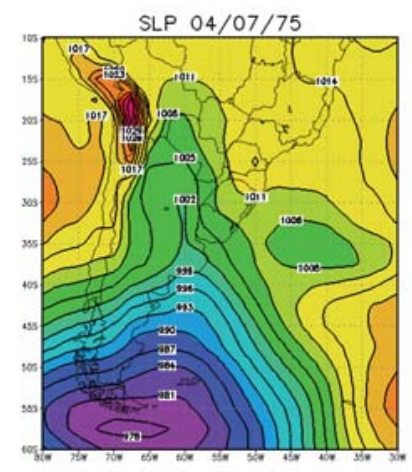

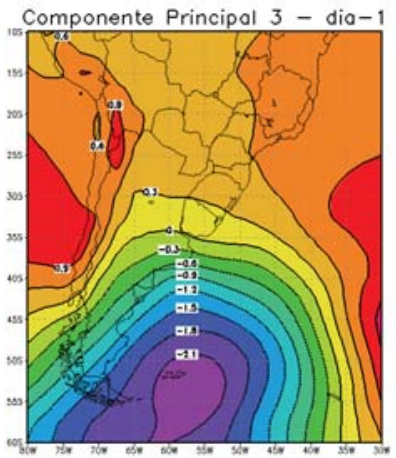
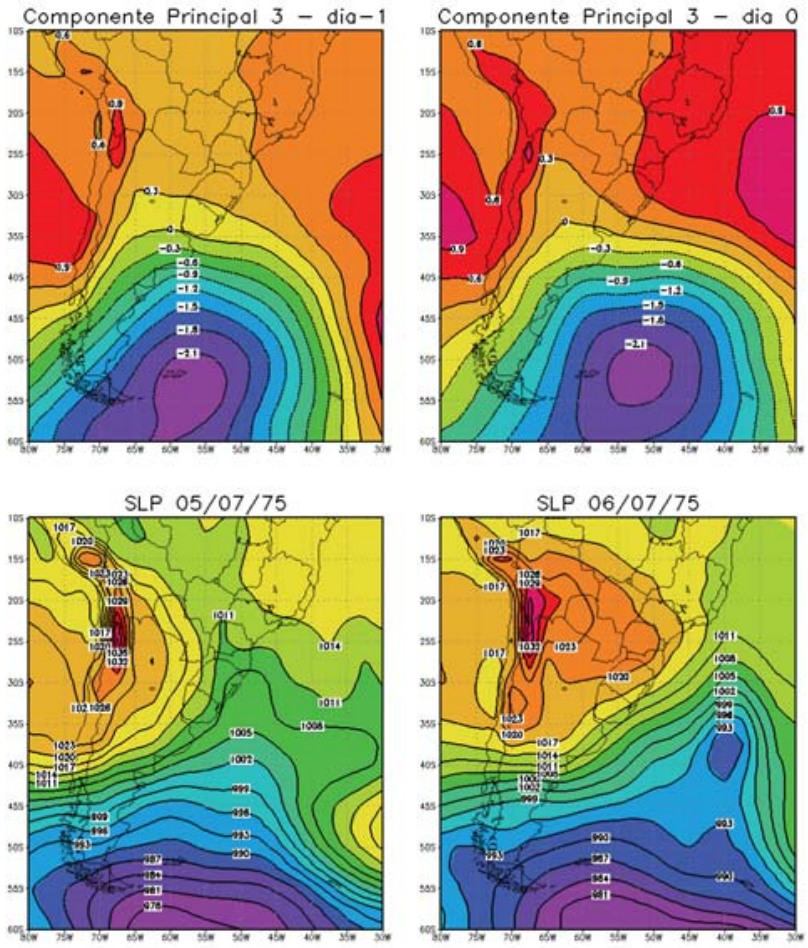

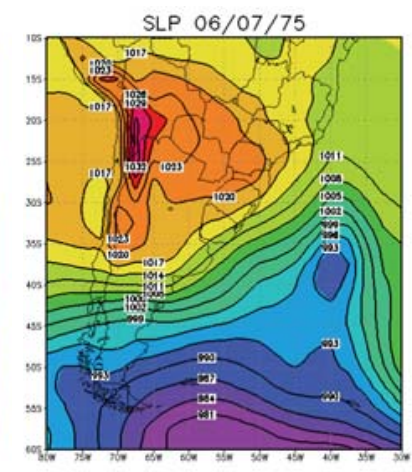

Figura 3 - (a) Terceira Seqüência de Componentes Principais (PSP 3) e (b) um caso observado de pressão em superfície altamente correlacionada (04/07/75 - 06/07/75). 
configuração similar à componente principal anteriormente assinalada. Observa-se uma crista e cavado no continente sul-americano deslocando-se lentamente para leste. No dia do evento (16/05/77), o cavado se estende desde o Atlântico Sul até o sul do Estado de Goiás. Desta maneira, grande parte dos Estados de São Paulo, Minas Gerais e Rio de Janeiro ainda encontram-se afetados pela parte dianteira deste sistema. Em superfície, em função das características baroclínicas deste sistema, o anticiclone pós-frontal migratório já estaria atingindo o Estado de São Paulo, incluindo a capital. Por outro lado, sobre o Chile e parte da Patagônia na Argentina, já se pode observar uma intensa crista, orientada de noroeste - sudeste favorecendo a incursão de ar muito frio do sul do continente.

O segundo padrão de Seqüências Principais, PSP2, mostrado na Figura 5a apresenta um intenso cavado que se estende desde o Paraguai até o sul do continente, onde fecha um vórtice ciclônico. Esse cavado se intensifica e amplifica conforme se desloca lentamente para leste, no decorrer do período analisado (dia-2 até dia-0). A leste deste sistema de baixa pressão, sobre o Atlântico, há um anticiclone cuja crista associada se estende em direção ao continente. A seqüência de situações sinótica correspondente aos dias 6, 7 e 8/7/72 (Figura 5b) mostra um exemplo observado correlacionado com a componente principal analisada. Apesar de não apresentar uma alta correlação, principalmente sobre a área de estudo, nota-se em termos gerais como principal característica deste padrão, o deslocamento praticamente zonal de um intenso e amplificado cavado, orientado meridionalmente, desde a região centro-oeste do Brasil até o oceano Atlântico Sul. Em certas ocasiões é bastante comum obter algumas diferenças entre as componentes principais e os casos observados, uma vez que a componente principal representa um modelo padrão referente á um grupo de várias situações reais que nem sempre mostra altas correlações com cada evento individual. Neste trabalho, como os sistemas meteorológicos analisados pertencem à escala sinótica, a análise das componentes principais deve levar em consideração o comportamento geral desses sistemas. Neste caso particular, a característica principal é o intenso cavado associado a uma intensa frente fria em superfície que se desloca zonalmente.

No dia do evento (8/7/72), o cavado encontra-se bem pronunciado, estendendo-se desde o Estado de Mato Grosso do Sul até o Atlântico Sul, passando pelo centro-sul do Brasil. Essa forte amplificação, acompanhada de um intenso gradiente de altura geopotencial, permite determinar um intenso fluxo do sudoeste que atravessa boa parte da Argentina e favorece a incursão de ar frio sobre as regiões sul e sudeste do Brasil.

A Figura 6a mostra o terceiro Padrão de Seqüências Principais (PSP3), que representa 23,1\% da variância total. Este a)

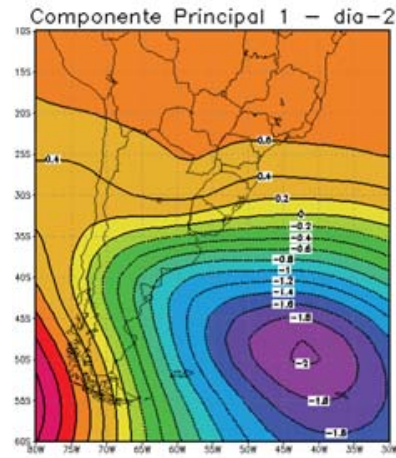

b)

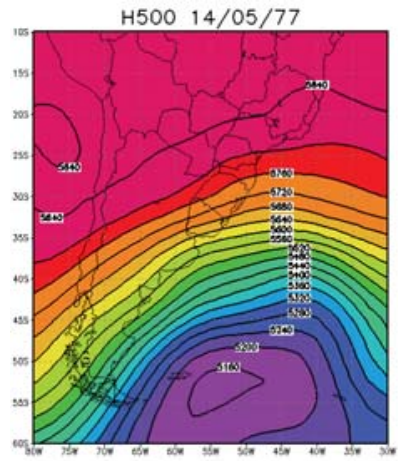

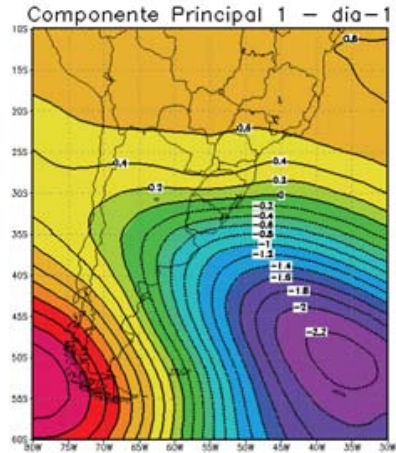

H50O 15/05/77

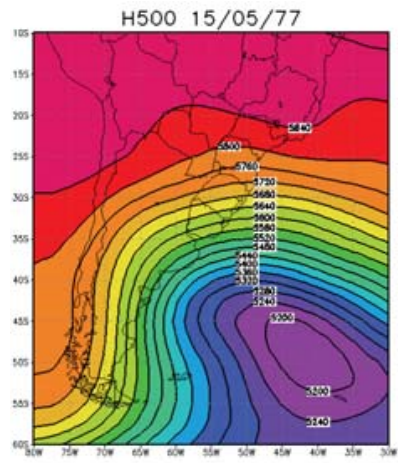

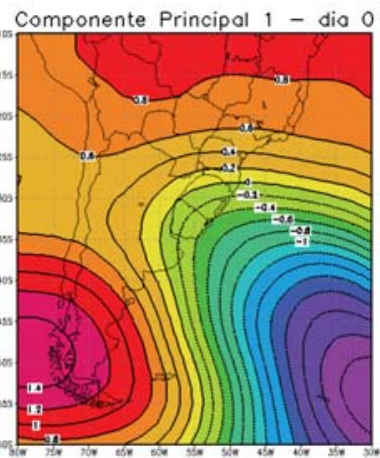

H500 16/05/77

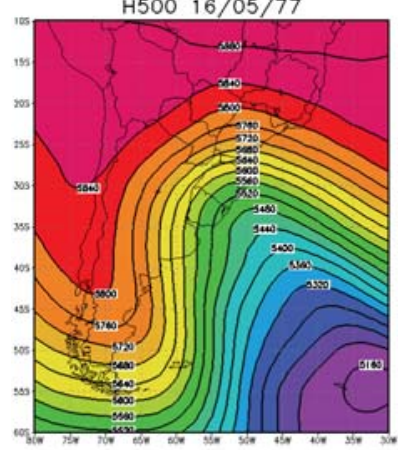

Figura 4 - (a) Primeira Seqüência de Componentes Principais (PSP 1) e (b) um caso observado de altura geopotencial em $500 \mathrm{hPa}$ altamente correlacionado (14/05/77 - 16/05/77). 
padrão de circulação em níveis médios da atmosfera apresenta uma configuração similar a um bloqueio no oceano Atlântico, com um anticiclone intenso centrado aproximadamente sobre o norte da Patagônia Argentina, e uma área de baixa pressão ao norte deste sistema, associado à presença de um cavado orientado zonalmente sobre o continente. Esse cavado apresenta um mínimo de vorticidade relativa sobre as regiões sul e sudeste do Brasil, e em várias ocasiões pode originar um vórtice ciclônico. No decorrer do período analisado (dia -2 até dia 0 ), a configuração em forma de dipolo determinada pelos dois sistemas, sofre um lento deslocamento para leste. Neste período pode-se observar a intensificação do anticiclone, bem como, do cavado associado ao sistema de baixa pressão.

$\mathrm{Na}$ Figura $6 \mathrm{~b}$ apresenta-se um caso real altamente correlacionado com a componente principal analisada. A característica principal desta seqüência é a presença de um vórtice ciclônico em níveis médios, que no dia -2 (5/8/87) aparece sobre o centro da Argentina e nos dias seguintes se desloca para o nordeste em direção ao sul do Brasil. Esse vórtice também mostra um cavado associado que se intensifica ao longo do período analisado, influenciando o tempo nas áreas de atuação. Esse padrão de circulação está geralmente associado a processos ciclogenéticos que afetam o nordeste da Argentina, Paraguai, Uruguai e parte das regiões sul e sudeste do Brasil. O ciclone extratropical formado em superfície favorece forte advecção de ar frio desde latitudes mais altas que atinge boa parte do Estado de São Paulo, incluindo a capital.

\subsubsection{Relação entre altitude e superfície}

Com o objetivo de analisar a estrutura vertical da circulação atmosférica associada a ondas de frio em São Paulo, foram relacionados os campos de altitude com aqueles de superfície. Essa relação foi feita a partir da análise das séries de "factor loadings" de cada uma das componentes principais em cada nível. A Tabela 5 mostra os coeficientes de correlação obtidos entre as séries de "factor loadings" de altitude e superfície.

Tabela 5 - Coeficientes de correlação entre as series de factor loadings de altitude e superfície.

\begin{tabular}{cccc}
\hline & PSP1 500 & PSP2 500 & PSP3 500 \\
\hline PSP1 Sup & 0,79 & $-0,47$ & $-0,33$ \\
PSP2 Sup & $-0,33$ & $-0,21$ & 0,88 \\
PSP3 Sup & -0.58 & 0,68 & $-0,06$ \\
\hline
\end{tabular}

As melhores relações entre todas as possíveis combinações para ambos níveis foram em ordem de importância, as seguintes: o primeiro padrão de seqüência principal de superfície a)

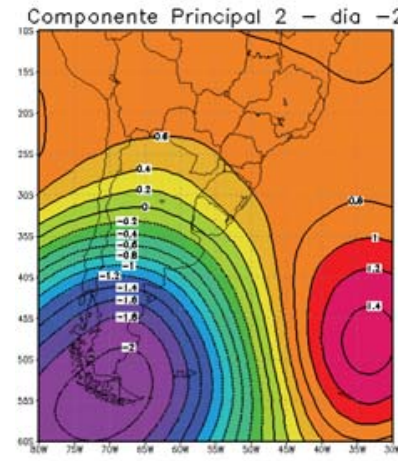

b)

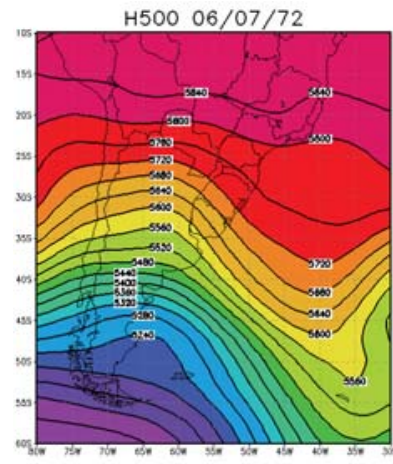

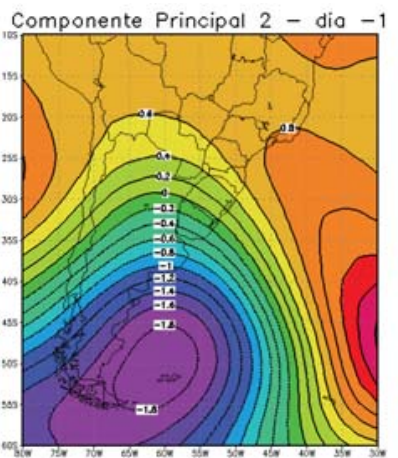

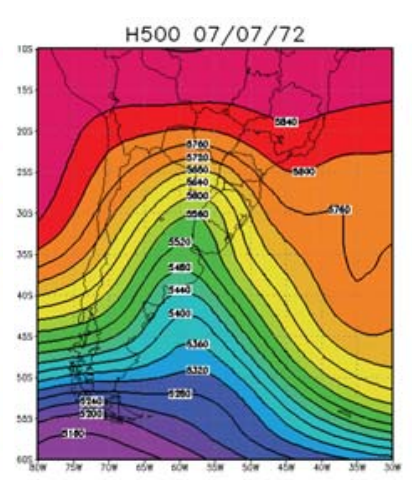

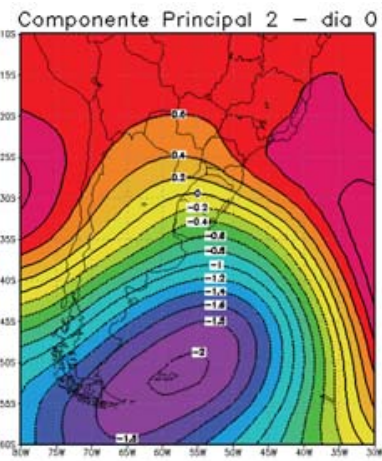

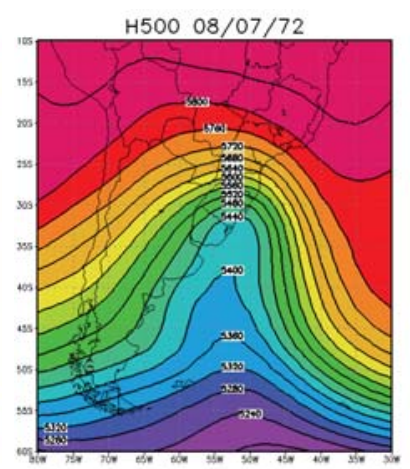

Figura 5 - (a) Segunda Seqüência de Componentes Principais (PSP 2) e (b) um caso observado de altura geopotencial em $500 \mathrm{hPa}$ correlacionado $(06 / 07 / 72-08 / 07 / 72)$. 
(PSP1 Sup) com o primeiro padrão de seqüência principal de 500 hPa (PSP1 500), o segundo padrão de seqüência principal (PSP2 Sup) com o terceiro padrão de seqüência principal de $500 \mathrm{hPa}$ (PSP3 500) e o terceiro padrão de seqüência principal de superfície (PSP3 Sup) com o segundo padrão de seqüência principal de $500 \mathrm{hPa}$ (PSP2 500).

\section{1) PSP1 Sup em superfície com PSP1 500 em $500 \mathrm{hPa}$} (correlação $=0,79)$.

A Figura 4a e a Figura 1a mostram as seqüências diárias em $500 \mathrm{hPa}$ e superfície, respectivamente, associadas a este par de padrões de circulação. Este é o modelo de circulação em superfície mais típico associado a incursões de ar frio sobre a região subtropical de América do Sul (Garreaud 2000; Vera e Vigliarolo 2000, Lupo et al. 2001, Escobar et al. 2004).

Em $500 \mathrm{hPa}$ (Figura 4a) pode-se observar a presença de uma intensa crista, com anticiclone associado, que está orientada quase meridionalmente, indo desde o oceano Pacífico até o sul do continente sul-americano. Ao mesmo tempo, sobre o oceano Atlântico Sul há um intenso sistema de baixa pressão do qual se estende um cavado em direção ao continente. Desta maneira, se estabelece um forte gradiente zonal de altura geopotencial ao sul da região sul do Brasil, que determina um fluxo intenso desde o sul do continente que favorece a entrada de ar frio até latitu- des mais baixas, incluindo o sul da região sudeste e boa parte do centro-oeste do Brasil. A persistência deste tipo de padrão de circulação em níveis médios da atmosfera produz ventos constantes de quadrante sul que também favorece passagem freqüente de sistemas migratórios em superfície.

Em superfície (Figura 1a), pode-se observar a entrada de um intenso anticiclone pós-frontal entre as latitudes $40^{\circ}$ e $50^{\circ} \mathrm{S}$, que no dia do evento (dia 0 ) atinge as regiões centro-oeste e sudeste do Brasil. Resultados semelhantes referentes à trajetória dos anticiclones migratórios que ingressam no continente sul americano foram encontrados por Lima e Satyamurty (1991) e Alessandro (1998). Sobre o Atlântico Sul tem-se um intenso ciclone extratropical associado à frente fria, que afetou boa parte do centro-sul do continente. A combinação de ambos sistemas de pressão (alta e baixa, respectivamente) favorece forte advecção de ar frio sobre as regiões sul, Sudeste e centrooeste do Brasil.

\section{2) PSP2 Sup em superfície com PSP3 500 em $500 \mathrm{hPa}$ (correlação $=0,88)$.}

A Figura 6a e Figura 2a determinam um padrão de circulação em altitude e em superfície associado a um processo de ciclogênese sobre o oceano Atlântico, na altura da região sul do Brasil. a)

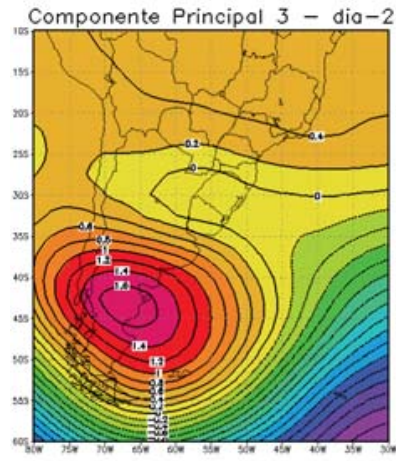

b)

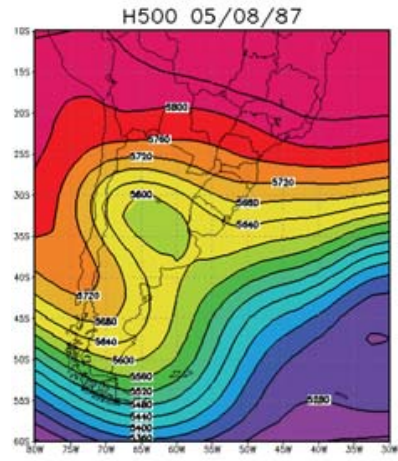

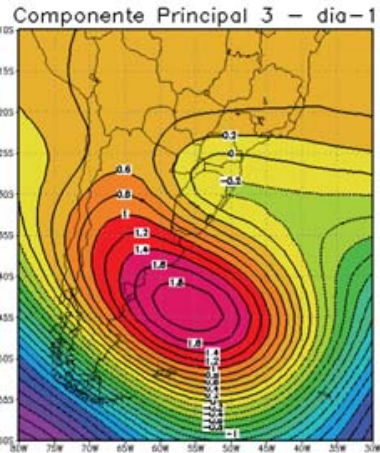

H500 06/08/87

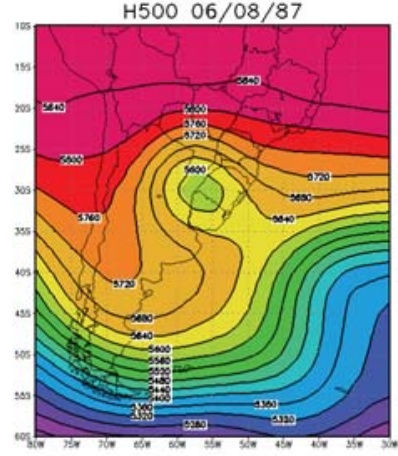

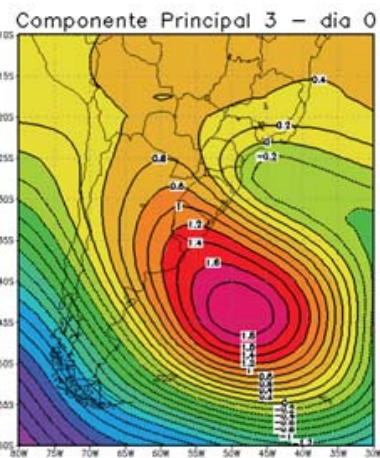

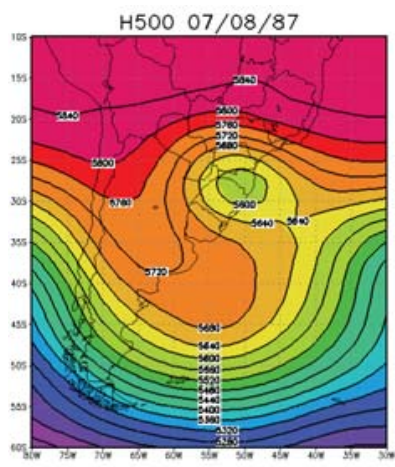

Figura 6 - (a) Terceira Seqüência de Componentes Principais (PSP 3) e (b) um caso observado de altura geopotencial em $500 \mathrm{hPa}$ altamente correlacionado (05/08/87 - 07/08/87). 
A circulação em 500 hPa (Figura 6a) mostra um cavado orientado quase zonalmente que se estende desde o oceano Atlântico em direção ao continente. Em várias ocasiões esse cavado pode-se intensificar e originar um vórtice ciclônico ou baixa fria desprendida que se desloca lentamente para a região subtropical da América do Sul e favorece o desenvolvimento de eventos ciclogenéticos no oceano Atlântico, próximo da costa leste do continente. Simultaneamente, pode-se observar um intenso anticiclone na Patagônia, Argentina, que também se desloca lentamente para leste em direção ao oceano Atlântico. Este padrão de circulação se mantém quase estacionário e devido ao seu lento deslocamento no decorrer do período analisado, apresenta uma configuração tipo bloqueio. Em superfície (Figura 2a) há um reflexo do padrão de altitude descrito anteriormente. Isto significa um intenso anticiclone que abrange boa parte do sul do continente e parte do oceano Atlântico. Ao norte deste centro de alta pressão observa-se um cavamento nas isóbaras que representa uma área de baixa pressão relativa. A partir do dia -1, esta área de baixa pressão começa a intensificar-se formando um ciclone extratropical no dia do evento (dia 0 ). O sistema de baixa pressão em superfície tem associado um ramo frontal frio que afeta parte das regiões sudeste e centro-oeste do Brasil. A presença deste ciclone contribui para a advecção de ar frio que se inicia com características marítimas e começa a secar conforme avança pelo interior do continente. Desta maneira, o ar frio chega a São Paulo mais seco e provoca um acentuado declínio nas temperaturas. Segundo Vera et al. (2002), este modelo padrão de circulação concorda com uns dos principais padrões sinóticos que ocorrem no período do inverno sobre América do Sul. Esse modelo está associado com a passagem de sistemas sinóticos migratórios por latitudes do Jato Subtropical $\left(30^{\circ} \mathrm{S}\right)$.

3) PSP3 500 em superfície com PSP2 500 em 500 hPa (correlação $=0,68)$.

Este padrão de circulação mostra o típico avanço de um sistema frontal frio com trajetória predominantemente zonal. Tanto em 500 hPa (Figura 5a) quanto em superfície (Figura 3a) nota-se a presença de um intenso sistema de baixa pressão no sul do continente associado à frente fria que atravessa principalmente pela região Sul do Brasil. Nas seqüências dos campos de pressão em superfície não é possível identificar claramente o anticiclone pós-frontal associado à passagem da frente, devido ao rápido avanço do sistema. De qualquer maneira, a intensificação da pressão observada sobre o Sudeste do Brasil entre o dia 0 e dia -1, ajuda a identificar a passagem deste sistema por latitudes um pouco mais baixas em relação aos modelos anteriores. Embora este padrão de circulação não seja tão significativo quanto aos dois restantes, também está associado a incursões de ar frio sobre as regiões sul e sudeste do Brasil.

\section{CONCLUSÕES}

A análise da variabilidade dos campos de circulação em superfície e altitude associada com ondas de frio na cidade de São Paulo mostra que existem diferentes padrões de circulação que podem produzir declínios significativos de temperatura.

Foram encontrados três padrões de sequências principais que representam aproximadamente $70 \%$ dos casos. Aproximadamente $50 \%$ desses casos estão associados à passagens de sistemas frontais frios que avançam desde Argentina, mas com diferentes posições e intensidade do anticiclone pós-frontal. Os demais casos estão associados a processos ciclogenéticos no oceano Atlântico, na altura das regiões sul e sudeste do Brasil.

O padrão de circulação mais típico mostra o ingresso de uma frente fria com trajetória sudoeste/nordeste e seu anticiclone pós-frontal ingressando no continente por latitudes altas, próximas aos $47^{\circ} \mathrm{S}$. A circulação em níveis médios da atmosfera mostra uma intensa crista no oceano Pacífico, próximo à costa do Chile, e um cavado se estendendo desde o interior do continente até o oceano Atlântico Sul. Desta maneira, o fluxo configurado favorece a penetração dos sistemas migratórios até as regiões centro-oeste e sudeste do Brasil. Este modelo padrão de circulaçao é similar ao descrito por Garreaud (2000) e Cavalcanti e Kousky (2003) quando analisaram a evolução de ondas de frio na América do Sul.

O segundo modelo de circulação está associado a eventos de ciclogênese no oceano Atlântico na altura da região sul do Brasil. A onda frontal formada durante o dia do evento (dia 0) é o sistema meteorológico responsável por provocar advecção do ar mais frio desde o sul. O campo de altura geopotencial em $500 \mathrm{hPa}$ apresenta uma configuração "tipo Bloqueio", isto significa um intenso anticiclone no centro-sul da Argentina e uma área da baixa pressão relativa ao norte deste sistema. Com este tipo de padrão de circulação, tanto em superfície como em $500 \mathrm{hPa}$, o ar frio chega a São Paulo mais seco favorecendo à ocorrência de temperaturas mínimas mais baixas. Este modelo padrão é bastante similar a alguns dos principais padrões sinóticos encontrados por Vera et al. (2002) e por Pezza e Ambrizzi (2005).

O terceiro modelo padrão está relacionado com a passagem de uma frente fria com trajetória predominantemente zonal, que tem associada um intenso sistema de baixa pressão no sul do continente. Em altitude, nota-se um intenso cavado, com vórtice fechado no sul do continente, refletindo o campo de pressão superfície. A orientação quase meridional deste cavado favorece o rápido avanço para leste dos sistemas transientes associados à mudanças significativas do tempo.

A análise dos três principais padrões de sequências de circulação em superfície e altitude permite identificar a evolução 
temporal dos sistemas sinóticos que determinam acentuados declínios de temperatura na cidade de São Paulo e pode contribuir objetivamente para melhoraria da previsão de tempo.

\section{AGRADECIMENTOS}

O autor agradece à estação meteorológica do IAG/USP pelo fornecimento dos dados e ao CNPq pelo suporte financeiro através da Bolsa de Desenvolvimento Tecnológico Industrial, nível 7A (Processo número 650007/02-6).

\section{REFERÊNCIAS BIBLIOGRÁFICAS}

ALESSANDRO, A. P. Contribuciones al estúdio de la Climatologia Sinóptica en la Argentina. 1998. Doutorado em Meteorologia. Faculdade de Ciências Exatas e Naturais, Universidade de Buenos Aires, Buenos Aires, 1998.

CATTELL, R. The scientific use of factor analysis: in Behavioral and Life Sciences. Plenum Press. New York amd London, 1978.

CAVALCANTI, I. F. A.; KOUSKY, V. E. Climatology of South American cold fronts. In : VII INTERNATIONAL CONFERENCE ON SOUTHER HEMISPHERE METEOROLOGY AND OCEANOGRAPHY, 2003, Wellington, New Zealand. 1 CD-ROM.

CERNE, S.B.; RUSTICUCCI, M.M. Estudio de la situación sinóptica asociada con la ola de frio extrema de febrero de 1996. Meteorologica, v. 22, n. 3, p. 5-17, 1997

COMPAGNUCCI, R.; SALLES, M.A. Surface Pressure Patterns during the year over Southern South America. Int. J. Climatol, v. 17, n. 6, p. 635-653, 1997

COMPAGNUCCI, R.; ARANEO, D. CANZIANI, P. Principal sequence pattern analysis: A new approach to classifying the evolution of atmospheric systems. Int. J. Climatol, v. 21, n. 2, p. 197-217, 2001.

DAPOZZO, J.; SILVA DIAS, M.A F. Um estudo de caso de penetração do ar polar em latitudes baixas: julho de 1998. In: CONGRESSO BRASILEIRO DE METEOROLOGIA, 8., 1994, Belo Horizonte. Anais: 1994. p. 601-606.

ESCOBAR, G.; BISCHOFF, S. Meteorological situations associated with significant temperature falls in BuenosAires: am aplication to the daily consumption of residential natural gas. Meteorol. Appl., v. 6, n. 3, p. 253-260, 1999.
ESCOBAR, G. C. J.; BISCHOFF, S. Criterio de detección de irrupciones de aire frío en la region central de Argentina a partir de descensos interdiurnos de temperatura. Meteorologica, v. 26, n. 1 y 2, p. 57-68, 2001.

ESCOBAR, G. C. J.; COMPAGNUCCI, R. H.; BISCHOFF, S. A. Sequence Patterns of $1000 \mathrm{hPa}$ and $500 \mathrm{hPa}$ geopotential height fields associated with cold surges in Buenos Aires. Atmosfera, v 12, n. 2, p. 69-89, 2004.

FORTUNE, M.; KOUSKY, V. Two severe freezes in Brazil: Precursors and Synoptic Evolution. Mon. Wea. Rev, v. 111, n. 1, p. 181-196, 1983.

GREEN, P. Analysing Multivariate Data. The Dryden Press. Illinois, U.S.A, 519, 1978.

HARMAN, H. Modern Factor Analysis. The University of Chicago Press Chicago, IL, 1976.

KALNAY, E.; KANAMITSU, M.; KISTLER, R.; COLLINS, W.; DEAVEN, D.; GANDIN, L.; IREDELL, M.; SAHA, S.; WHITE, G.; WOOLLEN, J.; JANOWIAK, J.; MO, KC.; ROPELEWSKY, C.; WANG, J.; LEETMAA, A.; REYNOLDS, R.; JENNE, R.; JOSEPH, D. The NCEP/ NCAR 40-year reanalysis Project. Bull. Am. Meteorol. Soc, v. 77, n. 3, p. 437-471, 1996.

KRISHNAMURTY, T.; TEWARI, M.; CHAKRABORTY, D. Downstream Amplification: A Possible Precursor to Mayor Freeze Events over Southeastern Brazil. Weather and Forecasting, v. 14, n. 2, p. 242-270, 1999.

LUPO, A. R.; NOCERA, J. J.; BOSART, L. F. South American cold surges: types, composites, and cases stydies. Mon. Wea Rev, v. 129, n. 5, p. 1021-1041, 2001.

MARENGO, J.; CORNEJO, A.; Satyamurty, P.; Nobre, C. Cold surges in tropical and extratropical South America: The Strong Event in June 1994. Mon. Wea Rev, v. 125, n. 11, p. 2759-2786, 1997.

Muller, G. V.; COMPAGNUCCI, R.; Nuñez, M.N.; SALLES, A. Surface circulation associated with frost in the wet pampas. Int. J. Climatol, v. 23, n. 8, p. 943-961, 2003.

PARMENTER, F. C. A Southern Hemisphere cold front passage at the equator. Bull. Amer. Meteor. Soc., v. 57, p. 1435$144,1976$. 
PEZZA, A.B.; AMBRIZZI, T. Ondas de frio na América do Sul e temperaturas geladas em são Paulo: análise histórica (1888 2003) e estudos de casos e trajetórias de ciclones e anticiclones. Rev. Bras. de Meteorologia, v. 20, n. 1, p. 141- 158, 2005.

RICHMAN, M. Specification of complex modes of circulation with T-mode factor analysis. In: II INTERNATIONAL CONFERENCE ON STATISTICS AND CLIMATE, 1983, Lisbon. Anais, National Institute of Meteorology and Geophysics, 1983. p. 511-518.

RICHMAN, M. Rotation of Principal Components. J.of Climatology, v. 6, n. 3, p. 293-335, 1986.

RICHMAN, M.; ANGEL, J.; GONG, X. Determination of Dimensionality in Eingenanalysis. In: V INTERNATIONAL MEETING ON STATSTICAL CLIMATOLOGY, 6, 1992, Canada. Anais: 1992. p. 229-235.

RUSTICUCCI, M.; VARGAS, W. Synoptic situations related to spells of extreme temperatures over Argentina. Meteorol. Appl, vol. 2, p. 291-300, 1995.

SATYAMURTY, P.; FONSECA, J. F. B.; BOTINO, M.J.; SELUCHI, M.E.; LOURENÇO, M.C.M.; GONÇALVES, L.G. An early freeze in southern Brazil in April 1999 and inst NWP guidance. Meteorol. Appl, v. 9, n. 1, p. 113-128, 2002.
SELUCHI, M.E.; NERY, J. T. Condiciones meteorológicas asociadas a la ocurrencia de heladas en la región de Maringá. Revista Brasileira de Meteorología, v. 7, n. 1, p. 523-534, 1992.

SENTELHAS, D.C.; FAZUOLI, L.C.; PEZZOPANE, J.R.M. Temperatura letal de diferentes espécies e derivados de híbrido interespecífico de café. In.: CONGRESSO BRASILEIRO DE PESQUISAS CAFECIRAS, 1995. Anais: p. 21.

SIAN, B. Situación sinóptica asociada a las temperaturas extremas observadas en junio de 1967. Meteorologica, v. 1, n. 1, p. $22-37,1970$.

SINCLAIR, M. A Climatology of Anticyclones and Blocking for Southern Hemisphere. Mon. Wea. Rev, v. 124, n. 2, p. 245-263, 1996.

VERA, C. S.; VIGLIAROLO, P.K. A Diagnostic Study of Cold - Air Outbreaks over South America. Mon. Wea. Rev, v. 128, n. 1 , p. $3-24,2000$.

VERA, C. S.; VIGLIAROLO, P.K.; BERBERY, E.H. Cold Season Synoptic-Scale Waves over Subtropical South America. Mon. Wea. Rev, v. 130, n. 3, p. 684-699, 2002. 